\title{
STUDY OF SERIAL EVALUATION OF SERUM CHOLINESTERASE LEVEL AS A PROGNOSTIC INDICATOR IN PATIENTS OF ORGANOPHOSPHOROUS POISONING
}

\author{
Alla Penchala Narasimha Rao, Sanampudi Lakshmi² \\ ${ }^{1}$ Assistant Professor, Department of Pharmacology, Kurnool Medical College, Kurnool, Andhra Pradesh. \\ ${ }^{2}$ Assistant Professor, Department of Physiology, Kurnool Medical College, Kurnool, Andhra Pradesh.
}

ABSTRACT
BACKGROUND
Organophosphates represent a class of highly toxic compounds that are used as insecticides, pesticides as well as nerve gas. An
estimated 3 million cases of pesticide poisoning with 2000 deaths occur all over the world every year. ${ }^{1}$
The aim of the study was to evaluate the benefit of serial estimation of serum cholinesterase levels in patients with
organophosphorous poisoning.

\section{MATERIALS AND METHODS}

The present study was done in 50 patients of O.P. poisoning who were admitted to Acute Medical Care Unit at GGH, Kurnool, from September 2011 to November 2011. Determination of serum cholinesterase ${ }^{2}$ is done by photometry.

\section{RESULTS}

The incidence of O.P. poisoning was $26 \%$ in the age group of 12 - 20 years, $48 \%$ in the age group of 21 - 30, 18\% in the age group 3140 years, $8 \%$ in 41 - 50 years' age group. The mean SChE at the time of admission was $2.9 \mathrm{KU} / \mathrm{L}$, which increased to 3.7 in $24 \mathrm{hrs}$. and to $5.2 \mathrm{in} 72 \mathrm{hrs}$. of hospitalisation. Mortality was $10 \%$ in patients who reported between 30 mins. to 3 hrs. Out of 18 patients who were admitted between 3 - 6 hrs. 4 patients died and in between 6 - 9 hours 2 patients out of 15 died. Mortality was $25 \%$ in patients who reported between 9 to $12 \mathrm{hrs}$. The mortality among the patients who had serum ChE levels of $10-20 \%$ of normal was $18 \%$, which increased to $100 \%$ when the serum levels were below $10 \%$. All the patients who died belonged to severe clinical grade of poisoning.

\section{CONCLUSION}

Serum cholinesterase inhibition is well correlated with clinical severity in case of severe poisoning. In patients with statistically significant rise in serum cholinesterase levels, chance of survival is high. In those patients who died within 72 hours, recovery of serum cholinesterase is not statistically significant. Therefore, assessing serum cholinesterase level serially up to 72 hours of poisoning can be useful and complimentary to clinical assessment in grading severity and predicting outcome.

\section{KEYWORDS}

Enzyme Aging, Organophosphorous Poisoning, Pin Point Pupil, Serial Estimation, Serum Cholinesterase.

HOW TO CITE THIS ARTICLE: Rao APN, Lakshmi S. Study of serial evaluation of serum cholinesterase level as a prognostic indicator in patients of organophosphorous poisoning. J. Evolution Med. Dent. Sci. 2016;5(104):7611-7615, DOI: 10.14260/jemds/2016/1720

\section{BACKGROUND}

Organophosphates represent a class of highly toxic compounds that are used as insecticides, pesticides as well as nerve gas. Acute organophosphorous poisoning ranks foremost among the list of agents, which cause acute pesticide poisoning. An estimated 3 million cases of pesticide poisoning with 2000 deaths occur all over the world every year. [1] In the past four decades more than 50,000 organophosphorous compounds have been synthesised and tested for insecticidal activity.

Organophosphorous compounds inactivate acetylcholinesterase, thus rendering it unable to hydrolyse acetylcholine. The cholinergic transmission time is extended

Financial or Other, Competing Interest: None.

Submission 22-11-2016, Peer Review 06-12-2016,

Acceptance 22-12-2016, Published 29-12-2016.

Corresponding Author:

Dr. Alla Penchala Narasimha Rao,

Assistant Professor,

Department of Pharmacology,

Flat. No. 504, Brundhavan Pride,

A Camp, Kurnool-518002,

Andhra Pradesh.

E-mail: apnarasimharao8@gmail.com

DOI: $10.14260 /$ jemds $/ 2016 / 1720$ and this results in protracted cholinergic over stimulation at muscarinic and nicotinic receptors.

Following exposure, these anticholinesterases lead to three well-defined syndromes, i.e. initial life-threatening acute cholinergic crisis, which often requires management in intensive care unit. Intermediate syndrome in which cranial nerve palsies, proximal muscle weakness and respiratory muscle weakness are common and patients often require respiratory support and organophosphate induced delayed polyneuropathy [OPDN].2

The mortality varies from $4 \%-30 \%$ and there has been a decreasing trend in mortality and morbidity due to early administration of Atropine and Pralidoxime therapy, intensive care management and ventilator support for respiratory failure. ${ }^{3}$

This study evaluates the significance of analysing serum cholinesterase (pseudocholinesterase) activity in assessing severity, correlating with clinical course and to predict the outcome in organophosphorous poisoning.

The aim of the study was to evaluate the benefit of serial estimation of serum cholinesterase levels in patients with organophosphorous poisoning and correlation of serum cholinesterase levels with clinical severity, monitoring clinical course and predicting the outcome along with the analysis of other parameters. 
Organophosphorous compounds inhibit enzyme acetylcholinesterase. The mechanism of inhibition of the enzyme is by reacting with the esteratic site on the acetylcholinesterase molecule. The bond formed between phosphorous atom and the esteratic site of enzyme is stable and requires hours to weeks to reverse depending on the type of organophosphorous compounds. Phosphorylated enzyme is inhibited because of occupation of its active site. It is incapable of carrying out its normal function of hydrolysing acetylcholine.

The effect of organophosphorous compound poisoning is therefore the result of continuing increased action of acetylcholine at the neuromuscular junctions resulting in a depolarisation block.

This phosphorylated enzyme can undergo spontaneous hydrolysis or dealkylation. Due to spontaneous hydrolysis, active enzyme cholinesterase is released and this is called reactivation. The phosphorylated enzyme can also undergo dealkylation. Once this occurs, reactivation is impossible. This process is called aging. ${ }^{4}$ Once aging occurs, recovery of cholinesterase activity depends on synthesis of new enzyme by liver, which may take days or weeks.

Organophosphorous compounds are divided into two series of compounds, alkylphosphates (Direct inhibitors) like malathion and aryl phosphates (Indirect inhibitors) like parathion. Poisoning by direct inhibitors of acetylcholinesterase presents as an acute cholinergic crisis, they do not develop late type muscular weakness. Response to atropine is rapid.

Indirect inhibitors do not develop signs of cholinergic crisis, but show persistent fasciculations along with sudden increase in atropine requirement. The incidence of development of late type of muscle weakness is high.

In acute poisoning, manifestations generally occur only after more than $50 \%$ of serum cholinesterase is inhibited and severity of manifestations parallels the degree of inhibition of serum cholinesterase activity.

- Mild poisoning - cholinesterase level reduces to $20 \%$ $50 \%$.

- Moderate poisoning - cholinesterase level reduces to $10 \%$ - 20\%.

- $\quad$ Severe poisoning - cholinesterase level reduces to less than $10 \%$.

The correlation between the degree of enzyme inhibition and the severity of manifestations is pertinent only in the initial stage of acute poisoning, inhibition is greater in repeated exposure. 5 Inhibition remains even after recovery from symptoms.

The toxicity varies from mild to highly toxic among various organophosphorous compounds.

TEPP, Mevinphos, Chlorpyrifos, Ethyl parathion, Methyl parathion and Fenthion are highly toxic compounds.

Leptophos, Dichlorvos, DDVP, Trichlorfon, Ronnel, Malathion, Temephos are moderately toxic O.P. compounds.

Acute organophosphorous poisoning is characterised by the following clinical features depending upon receptors in various systems.

\section{Acute Cholinergic Syndrome \\ Ophthalmologic}

Miosis, lacrimation and blurred or dim vision.
Cardiovascular: Bradycardia, hypotension (cardiac muscarinic (M2) receptors) tachycardia, hypertension (nicotinic) dysrhythmias and conduction defects QT prolongation and ST and $\mathrm{T}$ wave anomalies (severe poisonings).

\section{Respiratory}

Bronchial hypersecretion and wheezing (Muscarinic), muscle weakness or paralysis of the respiratory center (Nicotinic), non-cardiogenic pulmonary oedema (severe exposure) Vocal cord paralysis, progressive respiratory distress and stridor.

\section{Neurological}

Headache, seizures, respiratory depression, coma, mental status changes, fatigue, lethargy, agitation, depression, hallucinations, slurred speech, ataxia and extrapyramidal manifestations (CNS muscarinic GABA-ergic antagonism, particularly in limbic and cortical structures).

\section{Gastrointestinal}

Excessive salivation. Gastrointestinal smooth muscle contractions resulting in nausea, vomiting, diarrhoea, faecal incontinence and intestinal cramping (Muscarinic).

\section{Genitourinary}

Urinary incontinence (Muscarinic).

\section{Haematologic}

Inhibition of acetylcholinesterase.

\section{Dermatologic}

Sweating (Muscarinic).

\section{Immunity}

Parathion suppresses both IgM and IgG. It elicits autoimmune reactions and impairs natural killer cell and cytotoxic $\mathrm{T}$-cell function.

\section{Musculoskeletal}

Skeletal muscle fasciculations and twitching, weakness and paralysis (Nicotinic).

\section{Metabolic and Endocrine}

An increase of plasma corticosterone, TSH concentrations, non-ketotic hyperglycaemia and glycosuria. Hyperamylasaemia occurred in $47 \%$ of patients poisoned with malathion.

\section{Teratogenicity}

Pre- and post-natal death and congenital abnormalities like vertebral, limb abnormalities, cleft palate, polydactyly and hydroureter. 6

\section{Temperature Regulation}

Hypothermia (Muscle paralysis and excessive diaphoresis).

\section{Intermediate Syndrome}

The term intermediate syndrome is derived from the fact that it arises between the period of early cholinergic syndrome and the late onset peripheral neuropathy. The intermediate syndrome, which occurs 24 to 96 hours after acute cholinergic crisis is characterised by the following clinical features like 
inability to lift the neck and sit or stand up, weakness in motor cranial nerves, proximal muscle weakness, areflexia and respiratory paralysis.

Complete recovery occurs within 4 - 18 days if adequate ventilatory support is provided. Parathion was the causative agent in up to $75 \%$ of these cases in a Medline search study between 1965 and 1995.

In nerve conduction studies, a $30 \mathrm{~Hz}$ decremental response represents a desensitisation type of neuromuscular blockade. It correlates with the presence of clinically recognisable intermediate syndrome. It can be considered as an electrodiagnostic marker for intermediate syndrome.

\section{Management of Organophosphorous Poisoning Dermal Exposure}

Contaminated clothing should be removed from the body, skin should be washed thoroughly with soap and water or with hypochlorite (household bleach). A Skin Decontaminating Kit Applicator pads impregnated with AMBERGARD 555 ionexchange resin and activated charcoal are rubbed over contaminated skin and discarded.7

\section{Gastric Lavage}

Gastric lavage should be done and is most effective within 30 minutes of ingestion of poison. Protect airway by placement in Trendelenburg and left lateral decubitus position or by endotracheal intubation.

\section{Lavage Fluid}

a) Lavage with 150 to 200 millilitres warm saline per wash (In children over 5 yrs. or adults) and 10 millilitres/kilogram body weight of normal saline in young children. Continue until lavage return is clear.

b) The volume of lavage return should approximate amount of fluid given to avoid fluid-electrolyte imbalance.

\section{Caution}

Avoid the risk of electrolyte imbalance and water intoxication and hypothermia in very young children and the elderly.

\section{Complications}

Aspiration, pneumonia, hypoxia, hypercapnia, mechanical injury to the throat, oesophagus or stomach, fluid and electrolyte imbalance.

\section{Activated Charcoal}

Charcoal as slurry (240 mL water/30 g charcoal).

\section{Usual Dose}

25 to $100 \mathrm{~g}$ in adults/adolescents, 25 to $50 \mathrm{~g}$ in children.

\section{Antidotes of Organophosphorous Poisoning}

There are two antidotes available for treatment of organophosphorous poisoning.

1. Atropine sulfate is an antidote, which antagonises both muscarinic and CNS effects, will not reverse nicotinic effects.

2. Pralidoxime is the pharmacological antidote, which reactivates the phosphorylated acetylcholinesterase enzyme.
The correlation between the degree of serum cholinesterase inhibition and the severity of manifestations is pertinent only in the initial stage of acute poisoning and inhibition is greater in repeated exposures, inhibition remains even after recovery from symptoms.

\section{MATERIALS AND METHODS}

The present group of study was done from September 2011 to November 2011; 50 consecutive patients of either sex aged between 16 to 50 years with organophosphate poisoning were included in the study. They were admitted to Acute Medical Care Unit (AMC) at Govt. General Hospital, Kurnool.

Presumptive diagnosis of organophosphate poisoning was made on the basis of history, circumstantial evidence and characteristic clinical features. Brief clinical history was taken at admission and clinical characteristics, basic laboratory investigations, treatment given, ventilatory parameters (if patient required ventilatory support) were evaluated and recorded on admission, at 24 hours and 72 hours. Simultaneously, blood samples were analysed for serum cholinesterase levels at same time intervals. Patients with liver disease, renal failure and women on contraceptive pills were excluded from the study.

\section{Determination of Serum Cholinesterase}

The method used here is photometry, which is the "optimised standard method according to the recommendation of the German Society of Clinical Chemistry (DGKC)."

\section{RESULTS}

Fifty cases of organophosphorous poisoning were studied for the estimation of serum cholinesterase levels, in correlating with clinical severity, predicting the outcome along with the analysis of other predictors of outcome.

\section{The Results are as Follows}

Total number of cases studied were 50 , out of which male patients were 29 and females 21 . The male: female ratio was 1.38. Total number of deaths were $8(16 \%)$, out of them 7 (87.5\%) were males and $1(12.5 \%)$ female.

Patient's age ranged from 12 - 50 years. Maximum incidence was $48 \%$ in the age group of $21-30$ years. The incidence was $26 \%$ in the age group of 12 - 20 years, $18 \%$ in age group 31 - 40 years and 8\% in 41 - 50 years' age group.

Mortality is high in patients who consumed dangerous compounds like monocrotophos and edifenphos.

\begin{tabular}{|c|c|c|c|}
\hline Age (Years) & No. of Patients & Mortality & Percentage \\
\hline $12-20$ & 13 & 0 & 00.0 \\
\hline $21-30$ & 24 & 3 & 12.5 \\
\hline $31-40$ & 09 & 2 & 22.2 \\
\hline $41-50$ & 04 & 3 & 75.0 \\
\hline
\end{tabular}

Table 1. Showing the Age Group, Incidence and Mortality

Incidence of males was higher in age group of 21 - 30 years (16 patients), in females it was higher in age group of $12-20$ (13 patients). Mortality was highest in the age group $41-50$ years (75\%) followed by $22.2 \%$ mortality in age group 31 - 40 years, $12.5 \%$ in the age group 21 - 30 and no mortality in the age group 12 - 20 . 


\begin{tabular}{|c|c|c|}
\hline $\begin{array}{l}\text { Organophosphorous } \\
\text { Compound }\end{array}$ & $\begin{array}{c}\text { No. of } \\
\text { Patients }\end{array}$ & Mortality \\
\hline Monocrotophos & 18 & $22 \%$ \\
\hline Chlorpyrifos & 6 & - \\
\hline Parathion & 5 & - \\
\hline Malathion & 4 & - \\
\hline Edifenphos & 2 & $50 \%$ \\
\hline Diazinon & 1 & - \\
\hline Trichlorovas & 1 & - \\
\hline
\end{tabular}

The frequency of poisoning by different organophosphorous compounds was 36\% monocrotophos, $12 \%$ chlorpyrifos, $10 \%$ parathion, $8 \%$ malathion, $4 \%$ edifenphos, $2 \%$ diazinon, $2 \%$ trichlorovas, $28 \%$ others.

In the present study, the time interval between consumption of poison and hospital admission ranged from less than 30 minutes to more than 12 hours. There was no mortality in patients who came to hospital within 30 minutes and after 12 hrs. Mortality was 10\% (1 out of 10 ) in patients who reported between 30 mins. to $3 \mathrm{hrs}$. Out of 18 patients who were admitted between 3 - 6 hrs. 4 patients (22.2\%) died and in between 6 - 9 hours 2 patients (13.3\%) out of 15 died. Mortality was 25\% in patients who reported between 9 to 12 hrs. (1 out of 4$)$.

\section{Clinical Grade and Mortality}

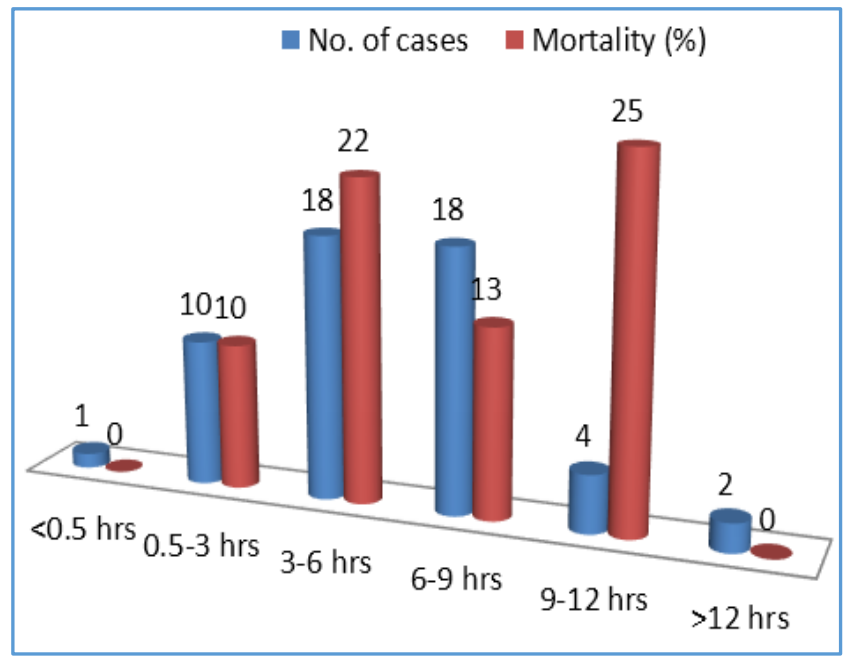

Figure 1. Bar Diagram showing

Clinical Grade and Mortality

The clinical grading of organophosphorous compound poisoning was done according to Dreisbach grading.

There was no mortality in patients belonging to mild grade and moderate grade of poisoning.

We found that mortality is associated with severe grade only. Out of 19 patients with severe clinical grade 8 died $(42.1 \%)$ mortality. There were no deaths in mild and moderate clinical grade of poisoning.

Total 7 patients required ventilator support, out of them 4 patients had Monocrotophos poisoning (57\%), 2 patients had Chlorpyrifos poisoning (29\%).

\begin{tabular}{|l|c|c|}
\hline \multicolumn{1}{|c|}{ Clinical Presentation } & No. of Patients & Percentage \\
\hline $\begin{array}{l}\text { 1. Salivation and } \\
\text { lacrimation }\end{array}$ & 38 & $76 \%$ \\
\hline 2. Abdominal cramps & 21 & $42 \%$ \\
\hline 3. Vomiting & 15 & $30 \%$ \\
\hline 4. Bradycardia & 34 & $68 \%$ \\
\hline 5. Fasciculations & 31 & $62 \%$ \\
\hline 6. Diarrhoea & 08 & $16 \%$ \\
\hline 7. Pinpoint pupil & 37 & $74 \%$ \\
\hline 8. Pulmonary oedema & 4 & $8 \%$ \\
\hline 9. Convulsions & 2 & $4 \%$ \\
\hline 10. Coma & 3 & $6 \%$ \\
\hline
\end{tabular}

\section{Table 3. Common Clinical Presentations} in OP Poisoning Patients

\section{Out of 50 patients}

- 06 - patients had $\mathrm{SChE}<10 \%$ of normal.

- 11 - patients had SChE $10 \%-20 \%$ of normal.

- 33 - patients had SChE $20 \%-50 \%$ of normal.

No patient had normal enzyme activity at admission.

SChE levels in controls or normal persons is $8.2 \mathrm{KU} / \mathrm{L}$. In patients of O.P. poisoning, the mean SChE levels at the time of admission is $2.9 \mathrm{KU} / \mathrm{L}$, which increased to $3.7 \mathrm{KU} / \mathrm{L}$ in $24 \mathrm{hrs}$. and $5.2 \mathrm{KU} / \mathrm{L}$ in $72 \mathrm{hrs}$.

SChE showed a trend of increase in activity with treatment with atropine and PAM during the course of hospital stay in organophosphorous poisoning.

Increase in activity of enzyme was statistically significant in various groups.

- SChE initial - SChE 24 hours $\mathrm{p}=<0.001$.

- SChE initial - SChE 72 hours $p=<0.0001$.

- SChE 24hrs - SChE 72 hours $\mathrm{p}=<0.0001$.

( $p<0.05$ is considered as statistically significant)

Recovery of serum cholinesterase is rapid as seen by analysing the enzyme activity at various intervals from admission to discharge in both groups of poisoning.

If the patient is surviving till 72 hours after poisoning, his/her SChE activity is up to $60 \%-70 \%$ of normal SChE activity.

In those patients who died within 72 hours, the recovery in enzyme activity was not statistically significant.

Out of the total 50 patients, 6 patients required ventilatory support. The number of days of ventilatory support were 1 to more than 5 days; 4 out of these 6 ventilated patients died.

Six patients who died on day 2 and 3 of hospital admission had severe poisoning. Their SChE was less than $10 \%$ at admission.

Their outcome was well correlated with the severity of poisoning. Three patients who died on day 3 of hospital admission had moderate poisoning as assessed by clinical grading and had SChE level (20\% - 50\%) of (normal).

Out of 6 patients who required ventilatory support ventilatory support.

- 5 patients had severe poisoning - $\mathrm{SChE}<10 \%$.

- 1 patient had moderate poisoning - SChE $10 \%-20 \%$.

- No patient had mild poisoning - SChE $20 \%-50 \%$. 


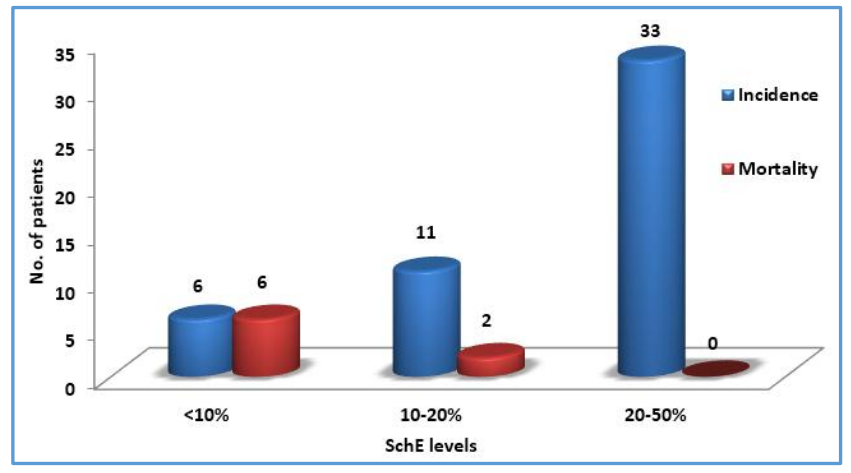

Figure 2. Bar Diagram showing Mean SChE Levels \& Mortality

\section{CONCLUSION}

50 cases of organophosphorous poisoning were studied to evaluate the factors that govern the severity and outcome of oisoning with special reference to serum cholinesterase levels.

There is a definite increase in mortality with increasing age. Highest mortality (75\%) is observed in the age group of 41 - 50 years. Though experimentally females are more susceptible to insecticide poison, majority of patients who have severe poisoning and have died are males (87.4\%). There is higher mortality with monocrotophos and edifenphos, which are most dangerous. There is no definite correlation with time interval between ingestion and admission at hospital and severity of poisoning. Serum cholinesterase inhibition is well correlated with clinical severity in case of severe poisoning. In patients with serum cholinesterase inhibition of mild and moderate levels, the clinical severity is approximately correlating. Serum cholinesterase level showed a trend towards increase in activity during hospital stay. In survivors recovery of serum cholinesterase level is rapid and reaches up to $60 \%-70 \%$ of normal within $72 \mathrm{hrs}$. In patients with statistically significant rise in serum cholinesterase levels, chance of survival is high. In those patients who died within 72 hours, recovery of serum cholinesterase is not statistically significant. Therefore, assessing serum cholinesterase level serially up to 72 hours of poisoning can be useful and complimentary to clinical assessment in grading severity and predicting outcome.

\section{Acknowledgements}

It gives me immense pleasure to take this opportunity to thank my professors Dr. B. Vasundhara Devi, M.D., Dr. Y. Vijaya Bhaskar Reddy, M.D. and Dr. S. Sharon Sonia, M.D for all the guidance, inspiration, moral support and encouragement during this study.

I extend my thanks to all my colleagues and friends for their cooperation and to all the patients who were part of my study.

I thank all the non-teaching staff members of our department for their co-operation during my study.

\section{REFERENCES}

1. WHO. Organophosphate insecticides: a general introduction. Environmental Health Criteria. No: 63 World Health Organisation Geneva 1986.

2. Ramani. Serum cholinesterase level as a indicator of prognosis in organophosphorous poisoning. JAPI 1988;36(1):23-4.

3. Desilva HJ, Wijewickrema R, Sennayake N. Does pralidoxime affect outcome of management in acute organophosphorous poisoning? Lancet 1992;339(8802):1136-8.

4. Maroni M. Review of toxiocological properties and biotransformation of organophosphorous esters in: WHO manual of analytical methods. Cremona 1985;3:39.

5. Namba T, Nolte CT, Jackrel J, et al. Poisoning due to organophosphate insecticides. Acute and chronic manifestations. Am Journal of Med 1971;50(4):475-92.

6. Stedman E. Studies on the relationship between chemical constitution and physiological action: Part II. The miotic activity of urethanes derived from the isomeric hydroxybenzyldimethylamines. Biochem J 1929;23(1):17-24.

7. Balani SG, Fernandes SO, Lakhani RH, et al. Diazinon poisoning. A report of 100 cases with particular reference to evaluation of treatment. JAPI 1968;16(11):911-7. 